\title{
India digs deep to build neutrino lab
}

India's high-energy physicists have been given the go-ahead to build an underground laboratory to study neutrinos.

The plan to investigate these elusive subatomic particles has been in the works since 2001. But the Department of Atomic Energy has now given it the green light and the nation's planning commission has approved its funding, says Naba Mondal, a physicist at the Tata Institute of Fundamental Research in Mumbai and spokesman for the project. It is expected to cost US $\$ 170$ million to build and should be online by 2012.

Home for the India-based Neutrino Observatory (INO) will be a man-made cave about 2 kilometres beneath the tallest peak of the Nilgiri Hills, 250 kilometres south of Bangalore. The rock above it will shield the observatory from unwanted cosmic radiation.

Initially, the lab will study neutrinos produced by cosmic rays in Earth's atmosphere. "A large experiment whose goal is to study atmospheric neutrinos has never been built," says Maury Goodman, a neutrino physicist at Argonne National Laboratory in Illinois. "In that way the INO is unique and important."

The INO will use a 50,000-tonne magnetized iron calorimeter to detect particles called muons that are produced on the rare occasions that neutrinos interact with matter. Because the detector can distinguish between muons with a positive and a negative charge, says Mondal, it should help researchers to work out the respective masses of the three types of neutrino.

John Learned, a physicist at the University of Hawaii at Manoa in Honolulu, says the iron detector is an "excellent choice" that will also allow the study of neutrino 'oscillations' - when one type of neutrino changes into another as it travels through space.

The INO aims to recapture the pioneering spirit of studies in a gold mine in Kolar,
"This could bring about a resurgence of the expertise in particle astrophysics in India." southern India, which led to the detection of atmospheric neutrinos in 1965 . But the facility was abandoned in 1992, and many researchers left for abroad.

Now, India wants to revitalize its neutrino physics community. The INO collaboration currently includes at least 100 scientists from 18 Indian institutions and the University of Hawaii. Learned says the project is likely to bring about "a resurgence of the expertise in particle astrophysics in India".

Project scientists are also in talks with US, Italian and Japanese researchers about collaborating, says Mondal.

K. S. Jayaraman

\begin{tabular}{|c|c|}
\hline Т 0207 & AMINOBUTYRIC ACID $\gamma-\left[2,3-{ }^{3} \mathrm{H}(\mathrm{N})\right]$ \\
\hline ARC 0290 & ARACHIDONIC ACID, $\left[1-{ }^{14} \mathrm{C}\right]$ \\
\hline ART 0196 & ARACHIDONIC ACID, $\left[5,6,8,9,11,12,14,15-{ }^{3} \mathrm{H}(\mathrm{N})\right]$ \\
\hline ARP 0148 & CERAMIDE-D-ERYTHRO-1-PHOSPHATE [33P] \\
\hline ART 1396 & COENZYME A [ $\left.{ }^{3} \mathrm{H}(\mathrm{G})\right]$ \\
\hline ARC 0111 & DeOXY-D-Glucose, 2-[1-14 C $]$ \\
\hline ART 0324 & FARNESYL PYROPHOSPHATE, $\left[1-{ }^{3} \mathrm{H}\right]$ \\
\hline ART 0348 & GERANYL GERANYL PYROPHOSPHATE, [1-3H] \\
\hline ART 0110 & GLUCOSAMINE HYDROCHLORIDE, D-[6-33] \\
\hline ART 0116 & INOSITOL, MYO-[2-3H] \\
\hline ARC 0126 & lODOANTIPYRINE, 4-[N-METHYL-14 C] \\
\hline iC 0541 & ISOPENTENYL PYROPHOSPHATE, $\left[1-{ }^{-14} \mathrm{C}\right]$ \\
\hline ART 0315 & MEVALONOLACTONE, RS-[5-3H] \\
\hline ART 0129 & PALMITIC ACID $[9,10-3 \mathrm{H}(\mathrm{N})]$ \\
\hline ARC 0772 & SPHINGOMYELIN, [METHYL-14C] \\
\hline ARP 0144 & SPHINGOSINE, D-ERYTHRO-1-PHOSHPATE [33P] \\
\hline ART 0778 & SPHINGOSINE, D-ERYTHRO [3-3H]-1-PHOSPHATE \\
\hline ART 0390 & STEAROYL $\left[9,10-3{ }^{3}\right]$ CoENEYME A \\
\hline & the \\
\hline
\end{tabular}

\begin{tabular}{|c|c|c|c|}
\hline $1 \mathrm{MCI}$ & $\$ 1226$ & $\$ 1292$ & $\$ 619$ \\
\hline $50 \mu \mathrm{Cl}$ & $\$ 1090$ & $\$ 1467$ & $\$ 549$ \\
\hline $50 \mu \mathrm{Cl}$ & $\$ 675$ & $\$ 927$ & $\$ 33$ \\
\hline $10 \mu \mathrm{Cl}$ & \multicolumn{2}{|c|}{ ARCEXCLUSIVE! } & $\$ 114$ \\
\hline $10 \mu \mathrm{Cl}$ & \multicolumn{2}{|c|}{ ARC EXCLUSNE! } & $\$ 9$ \\
\hline $1 \mathrm{MGl}$ & $\$ 2148$ & & $\$ 10^{-}$ \\
\hline $50 \mu \mathrm{Cl}$ & $\$ 990$ & $\$ 1000$ & 84 \\
\hline $250 \mu \mathrm{Gl}$ & $\$ 962$ & $\$ 1488$ & \\
\hline $5 \mathrm{MCl}$ & $\$ 1356$ & $\$ 1953$ & \\
\hline $5 \mathrm{MCl}$ & $\$ 2325$ & $\$ 2954$ & \\
\hline $1 \mathrm{MCI}$ & $\$ 2301$ & $\$ 2400$ & \\
\hline $50 \mu \mathrm{Cl}$ & $\$ 1539$ & $\$ 1573$ & $\$$ \\
\hline $5 \mathrm{MCl}$ & $\$ 2103$ & & $\$ 10$ \\
\hline $5 \mathrm{MCl}$ & $\$ 240$ & $\$ 573$ & \\
\hline $10 \mu \mathrm{Cl}$ & $\$ 1214$ & $\$ 1383$ & \\
\hline $10 \mu \mathrm{Cl}$ & \multicolumn{2}{|c|}{ ARCEXCLUSIVE! } & $\$ 11$ \\
\hline $10 \mu \mathrm{Cl}$ & \multicolumn{2}{|c|}{ ARC EXCLUSNE! } & $\$ 1<$ \\
\hline $50 \mu \mathrm{Cl}$ & & $\$ 2205$ & $\$ 1$ \\
\hline $250 \mu \mathrm{Cl}$ & $\$ 1570$ & & \\
\hline
\end{tabular}
American Radiolabeled Chemicals, INC. - 101 ARC Drive - SaINT LouIs, MO 63146 USA TEL: 314-991-4545 - FAX: 314-991-4692 - TOLL FrEE: 800-331-6661 - FAX: 800-999-9925 E-MAIL: ARCINC@ARC-INC.COM - WEB: WWWW.ARC-INC.COM - REQUEST A COPY OF OUR 2007 CATALOG! 